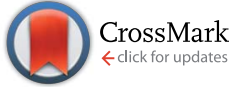

Cite this: RSC Adv., 2017, 7, 8314

Received 1st November 2016 Accepted 15th January 2017

DOI: 10.1039/c6ra26122a

www.rsc.org/advances

\section{Structural changes of poplar wood lignin after supercritical pretreatment using carbon dioxide and ethanol-water as co-solvents $\uparrow$}

\author{
Xing Wang, Yanzhu Guo,* Jinghui Zhou* and Guangwei Sun \\ To delineate the structural changes of lignin during supercritical carbon dioxide pretreatment with ethanol- \\ water as co-solvents (SCEP), enzymatic hydrolysis lignin (EHL) in original poplar chips, residual lignin in SCEP \\ pretreated residues (SCEP-RL) and lignin dissolved in the SCEP liquors (SCEP-DL) were sequentially isolated \\ and systematically characterized by GPC, quantitative ${ }^{13} \mathrm{C}-\mathrm{NMR},{ }^{31} \mathrm{P}-\mathrm{NMR}, 2 \mathrm{D}-\mathrm{HSQC}$ NMR and TGA. After \\ SCEP process, $19.2 \%$ of lignin was degraded and dissolved into SCEP liquors, while $4.8 \%$ of lignin was still \\ present in the pretreated residues. It was also convinced that parts of the $\beta-O-4$ aryl ether linkages were \\ cleaved and some of the stilbene, resinol $(\beta-\beta)$ and phenylcoumaran $(\beta-5)$ units were increased during \\ SCEP process. Furthermore, the contents of free phenolic hydroxyl groups and carboxylic acids in SCEP- \\ $\mathrm{RL}$ and SCEP-DL were higher than that of EHL.
}

\section{Introduction}

Lignocellulosic biomass is one of the most abundant yet underutilized bioresources on earth. It comprises large amounts of carbohydrates, such as cellulose and hemicelluloses, and is considered as a potential substrate to produce high value products, e.g. , biofuels including bioethanol and biogas. ${ }^{1,2}$ Bioethanol is typically produced from biomass via three steps: pretreatment of biomass materials, enzymatic hydrolysis of pretreated residues by cellulases and fermentation of sugars by microbial organisms. ${ }^{3}$ Among these steps, the pretreatment is crucial to efficiently conversing lignocellulosic biomass to ethanol, because it can highly break down the polymeric matrix between carbohydrates and lignin in biomass, and therefore decreases the recalcitrance of biomass and enhances the accessibility of enzymes to pretreated residues during enzymatic hydrolysis. ${ }^{4-6}$ Typical methods for biomass pretreatment include auto-hydrolysis and thermochemical pretreatment using alkali, ${ }^{7,8}$ acid, ${ }^{9}$ organic solvents, ${ }^{10,11}$ or supercritical fluid, ${ }^{12}$ which have been widely studied to prepare lignocellulosic substrates from a wide range of raw materials by either removing or redistributing hemicelluloses or lignin for subsequent bioconversion.

The supercritical carbon dioxide $\left(\mathrm{ScCO}_{2}\right)$ is a ubiquitous, nontoxic, recyclable and low-cost reagent, which has some favorable characteristics, e.g., environment friendly, low critical temperature and pressure, gas-like mass transfer, liquid-like

Liaoning Key Laboratory of Pulp and Papermaking Engineering, Dalian Polytechnic University, Dalian, Liaoning 116034, China.E-mail: guoyz@dlpu.edu.cn; zhoujh@ dlpu.edu.cn; Tel: +8641186323296

$\dagger$ Electronic supplementary information (ESI) available. See DOI: 10.1039/c6ra26122a solvating power, low viscosity and zero surface tension. Therefore, its employment in the biomass pretreatment generally can enhance the accessibility of biomass and reduce the pretreatment temperature. ${ }^{\mathbf{1 3 , 1 4}}$ Up to now, the technologies involving the application of supercritical carbon dioxide into the pretreatment have been extensively investigated with the aim of conversing lignocellulosic biomass to the bioethanol products. Commonly, a variety of organic solvents, such as ethanolwater, ${ }^{15}$ 1-butanol, ${ }^{16}$ acetic acid, ${ }^{17}$ are employed as the cosolvents during the process of $\mathrm{ScCO}_{2}$ pretreatment, which can selectively isolated lignin from biomass. Ethanol is an excellent liquefaction solvent for isolating lignin from biomass due to its lower dielectric ability, higher and rapider dissolving ability to the high molecular-weight lignin fraction. ${ }^{15,18}$ Recently, the $\mathrm{ScCO}_{2}$ pretreatment with ethanol-water as co-solvents (SCEP) has been applied into the pretreatment of various biomass materials, such as corn stover, ${ }^{19}$ sugarcane bagasse, ${ }^{20}$ rice straw, ${ }^{21}$ switchgrass, ${ }^{22}$ guayule ${ }^{23}$ and rice husk. ${ }^{12}$ Due to the enhanced acidic environment caused by $\mathrm{ScCO}_{2}$, the combination of $\mathrm{ScCO}_{2}$, ethanol and water seems to be superior in the removal of lignin from biomass. It has been reported that up to 90.6\% lignin was removed from biomass after SCEP, while the crystallinity and enzymatic digestibility of pretreated residues were not significantly changed. ${ }^{12}$ It is needed to notation that lignin in the pretreated residues has inhibiting property to enzyme for the subsequent enzymatic hydrolysis, because the enzyme is easily to bind on the surfaces of residues. Meanwhile, the lignin with different structures is also convinced to generate different inhibiting properties. ${ }^{24}$ Proper understanding of the structural changes of lignin during SCEP process is helpful to design suitable strategies for pretreatment and alleviates the negative effects of lignin on the enzymatic hydrolysis. 
In the present study, poplar wood chips were chosen as the raw materials and employed into the SCEP process and the structural changes of lignin during SCEP process were elucidated. Three lignin samples including EHL, SCEP-DL and SCEPDL were separately isolated from the original chips, the liquors and residual chips after SCEP. The structural features of these three preparations were comparatively investigated by quantitative ${ }^{13} \mathrm{C}-\mathrm{NMR}, 2 \mathrm{D}$-HSQC NMR and ${ }^{31} \mathrm{P}-\mathrm{NMR}$ spectroscopy. Their molecular weights were analysed by gel permeation chromatography (GPC). Thermogravimetric analysis (TGA) was also used to elucidate the relationship between their structure features and thermal properties.

\section{Materials and methods}

\subsection{Materials}

Poplar wood chips (dimension: $4 \times 4 \times 2 \mathrm{~cm}$ ) were collected from Tiger Forest \& Paper Co., Ltd. (Hunan, China). The moisture content in chips was $15.4 \pm 0.2 \mathrm{wt} \%$. Carbon dioxide $(99.99 \%$ purity) was supplied by Guangming Research and Design Institute of Chemical Industry (Tianjin, China). Cellulast (80 FPU per g) and Novozyme 188 (250 FPU per g) were provided by Novozymes, China. Other reagents were of analytical or chromatographic grades and directly used without purification.

\subsection{Supercritical pretreatment}

The supercritical carbon dioxide pretreatment of poplar chips was performed in a $1 \mathrm{~L}$ reactor (E1), which was connected with two $0.5 \mathrm{~L}$ separators in series (S1, S2) and a tank (ST1), for storage and recycle of $\mathrm{CO}_{2}$. The detail scheme for SCEP process is shown in Fig. S1.† $50 \mathrm{~g}$ of poplar wood chips and $500 \mathrm{~mL}$ of $50 / 50(\mathrm{v} / \mathrm{v})$ ethanol-water solution as co-solvent were charged into the reactor. After closed, the reactor was constantly pressurized with carbon dioxide to $20 \mathrm{MPa}$ for $1 \mathrm{~h}$ at $120{ }^{\circ} \mathrm{C}$. When experiments were finished, the liquid phase was collected from the separator in SCEP pretreatment systems. The pretreated poplar chips in the reactor were washed using ethanol-water solution $(50 / 50, \mathrm{v} / \mathrm{v})$ and dried in a cabinet oven with air circulation at $65{ }^{\circ} \mathrm{C}$ for $12 \mathrm{~h}$. The dried pretreated poplar chips were kept in sealed bags for further analysis.

\subsection{Preparation of lignin samples}

2.3.1. Preparation of SCEP-DL from SCEP liquor phase. After concentrated into $100 \mathrm{~mL}$ in a rotary evaporator (IKA, RV 10 , Germany) at $40{ }^{\circ} \mathrm{C}$, the collected liquid phase was poured into three volumes of acidic water $(\mathrm{pH} 1.0)$ to precipitate the dissolved lignin. After filtration, the precipitates were washed with acidic water solution ( $\mathrm{pH}$ 1.0) for several times. The further purified SCEP-DL sample was freeze-dried for $48 \mathrm{~h}$.

2.3.2. Preparation of lignin samples from the original or pretreated poplar chips. The method of enzymatic hydrolysis was employed to isolate lignin from the original and pretreated poplar chips in order to minimize damage to the structure of lignin during preparing process. After smashed into powder (20-60 mesh) by a crusher (FZ102, Tianjin Thai frost instrument Co., Ltd., China), the chips were then extracted with benzene/ ethanol $(2 / 1, v / v)$ solution for $8 \mathrm{~h}$ and finally vacuum dried at $60{ }^{\circ} \mathrm{C}$ for $24 \mathrm{~h}$. The dried powders were then grounded in a planetary micro mill (Pulverisette 7, Fritsch, Germany) for $48 \mathrm{~h} .10 \mathrm{~g}$ ball-milled powders were hydrolyzed by $0.12 \mathrm{~g}$ Cellulast and $0.10 \mathrm{~g}$ Novozyme $188 \mathrm{in} 500 \mathrm{~mL} 0.05 \mathrm{M}$ acetate buffer solution (pH 4.5) at $200 \mathrm{rpm}$ for $72 \mathrm{~h}$ in a rotary shaker. After isolating from the enzymatic hydrolysis mixture solutions by centrifugation, the hydrolyzed solid residues were extensively washed using hot water and then freeze-dried for $48 \mathrm{~h}$. The dried residues were suspended in acidic dioxane/water solution $(85 / 15, \mathrm{v} / \mathrm{v})$ containing $0.05 \mathrm{M} \mathrm{HCl}$ at $86{ }^{\circ} \mathrm{C}$ for $2 \mathrm{~h}$. After filtration and concentration, the filtrates were poured into three volumes of distilled water to precipitate crude lignin. To further remove some contaminants from the sample, the crude lignin was dissolved into $90 \%(\mathrm{v} / \mathrm{v})$ acetic acid solution and then precipitated using three volumes distilled water. After centrifugation and freeze-drying, the purified lignin was obtained. The lignin isolated from the original and pretreated poplar chips were named as (EHL) and SCEP-RL, respectively.

\subsection{Analytical methods}

The chemical compositions of original and pretreated poplar chips, including the amounts of sugars and lignin, were determined according to the National Renewable Energy Laboratory standard analytical method (NREL/TP-510-42618). ${ }^{25}$ Every experiment were repeated by two times. The contents of sugars in EHL, SCEP-RL and SCEP-DL samples were determined by ionic chromatograph (Dionex ICS-5000, USA), which was equipped with a Capillary Reagent-Free IC System and a CarboPac 20 column.

The NMR determinations for all of the prepared lignin samples were performed in a Bruker AVIII $400 \mathrm{MHz}$ spectrometer. For the ${ }^{13} \mathrm{C}$ NMR analysis, $140 \mathrm{mg}$ of lignin samples were dissolved in $0.5 \mathrm{~mL}$ of DMSO- $\mathrm{d}_{6}$. The ${ }^{13} \mathrm{C}$ NMR spectra were acquired in the FT mode at 100.6 MHz through employing an inverse-gated decoupling pulse sequence, which was conditioned with the following parameters: $30^{\circ}$ pulse angle, $2 \mathrm{~s}$ pulse delay, $1.4 \mathrm{~s}$ acquisition time and 30000 scans at room temperature. The signals in ${ }^{13} \mathrm{C}-\mathrm{NMR}$ spectra were assigned according to the previous literature. ${ }^{26}$ The 2D-HSQC NMR determination was carried out according to recently reported $\operatorname{method}^{27,28}$ with minor modification. Briefly, $140 \mathrm{mg}$ of lignin samples were dissolved in $0.5 \mathrm{~mL}$ DMSO- $\mathrm{d}_{6}$. The standard pulse program hsqcedetgpsisp2 was applied in the HSQC experiment. The spectral widths for the ${ }^{13} \mathrm{C}$ and ${ }^{1} \mathrm{H}$ dimensions were $20000 \mathrm{~Hz}$ and $5000 \mathrm{~Hz}$, respectively. The central solvent peak was used as an internal reference $\left(\delta_{\mathrm{C}} 39.5 ; \delta_{\mathrm{H}} 2.49\right)$. The application of ${ }^{31} \mathrm{P}-\mathrm{NMR}$ for characterization of functional groups contents in lignin moiety had been extensively explored. ${ }^{29}$ After dissolution of $20 \mathrm{mg}$ of lignin samples in $500 \mu \mathrm{L}$ of anhydrous pyridine $/ \mathrm{CDCl}_{3}$ solvents $(1.6: 1, \mathrm{v} / \mathrm{v})$ under magnetic stirring, $100 \mu \mathrm{L}$ internal standard solution including $10.85 \mathrm{mg} \mathrm{mL}^{-1}$ cyclohexanol in pyridine/ $\mathrm{CDCl}_{3}(1.6: 1, \mathrm{v} / \mathrm{v})$ and $100 \mu \mathrm{L}$ relaxation reagent solution containing $5 \mathrm{mg} \mathrm{mL}^{-1}$ chromiu$\mathrm{m}$ (III) acetylacetonate in pyridine/ $\mathrm{CDCl}_{3}(1.6: 1, \mathrm{v} / \mathrm{v})$ were added. Finally, $100 \mu \mathrm{L}$ 2-chloro-4,4,5,5-tetramethyl-1,3,2- 
dioxaphospholane (TMDP) was added into the above solution and the mixture was kept for $10 \mathrm{~min}$. The final phosphitylated sample was transferred into a $5 \mathrm{~mm}$ NMR tube for ${ }^{31} \mathrm{P}$ NMR determination.

The molecular weights of lignin preparations were analyzed by GPC, which were based on the procedures described in a previous literature..$^{30}$ The analysis for thermal stability of lignin sample was carried out on a TA Q500 thermal analyzer (TA Instruments, USA), which was processed by heating the samples from $30{ }^{\circ} \mathrm{C}$ to $700{ }^{\circ} \mathrm{C}$ with a $10{ }^{\circ} \mathrm{C} \mathrm{min}{ }^{-1}$ heating rate under the protection of nitrogen.

\section{Results and discussion}

\subsection{Composition analysis of lignin preparations, original and pretreated poplar chips}

In order to estimate the delignification efficiency during SCEP process, the chemical compositions of original and pretreated poplar chips were comparatively studied and the results are shown in Table 1. The total contents of sugars in original poplar chips was $72.7 \%$. Among of them, the xylose and glucose were the dominant sugars, and the arabinose, galactose, and mannose were only present with low contents. After pretreatment, the total contents of sugars and glucan in chips were separately increased up to $86.31 \%$ and $71.65 \%$. By contrast, the contents of hemicelluloses, containing xylan, arabinan, galactan and mannan, were decreased from $23.55 \%$ to $14.66 \%$, confirming that amounts of hemicelluloses were degraded and isolated from poplar chips after SCEP. The content of acid insoluble lignin (AIL) in original poplar chips was $23.4 \%$, while the content of acid soluble lignin (ASL) was small and only about $2.3 \%$. After SCEP, the total content of lignin in pretreated poplar chips was $7.5 \%$, including $6.7 \%$ AIL and $0.8 \%$ ASL. The above results indicated that about $79 \%$ of lignin was removed from original poplar chips after SCEP process. It had been convinced that the enzymatic hydrolysis efficiency of pretreated chips was higher than original chips, due to their lower contents of lignin. ${ }^{31}$ However, it was also reported that the lignin in the pretreated residues has inhibiting property to enzyme for the subsequent enzymatic hydrolysis, because the enzyme is easily to bind on the surfaces of residues. ${ }^{24}$ Therefore, it could be concluded that the correlation between lignin and enzymatic hydrolysis could not only be explained by the content of lignin. The effect of structural changes of lignin inducing by the removal of lignin on the enzymatic hydrolysis should be extensively explored. With the above aims, three lignin
Table 2 The yields and sugar compositions of lignin preparations

\begin{tabular}{lclllllll}
\hline & & \multicolumn{7}{c}{ Sugar compositions (wt\%) } \\
\cline { 3 - 9 } Samples & Yields $^{a}(\%)$ & Ara & Gal & Glu & Xyl & Man & Total \\
\hline EHL & 25.6 & 0.02 & 0.05 & 0.17 & 0.96 & 0.07 & 1.27 \\
SCEP-RL & 5.1 & 0.01 & 0.02 & 0.11 & 0.62 & 0.03 & 0.79 \\
SCEP-DL & 19.8 & Tr & Tr & 0.01 & 0.18 & Tr & 0.19
\end{tabular}

${ }^{a}$ Yield $=W_{\mathrm{L}} / W_{\text {material }} \times 100 \%$, where $W_{\mathrm{L}}$ is the weight of the EHL, SCEPDL or SCEP-RL (mg), $W_{\text {material }}$ is the weight of the initial raw material (mg).

preparations were isolated and characterized in this study. The yields and sugar contents of EHL, SCEP-RL and SCEP-DL are shown in Table 2. The yield of EHL from original poplar chips was $25.6 \%$, while the yield of SCEP-RL from pretreated poplar chips was $5.1 \%$. The yield of SCEP-DL, recovered from the pretreatment liquors, was $19.8 \%$. All of the above results were consistent with the contents of lignin shown in Table 1. The contents of total sugars in these three preparations were $1.27 \%$, $0.79 \%$ and $0.19 \%$, indicating that the preparations were purity enough to be characterized by NMR. The xylan was the major sugars in EHL, SCEP-DL and SCEP-RL. However, it was observed that the contents of total sugars, especially xylan, in SCEP-DL and SCEP-RL were lower than those in EHL, implying that the hemicelluloses attached to lignin were partially degraded during the SCEP process.

\subsection{D-HSQC NMR analysis}

The 2D-HSQC NMR is a powerful analytic technique and can give detailed structural characterization of complex biopolymers such as lignin..$^{5,32,33}$ The 2D-HSQC spectra of EHL, SCEP-RL and SCEP-DL samples are shown in Fig. 1. Based on the previous literatures, ${ }^{27}$ the main signals were assigned and the detected linkages are depicted in Fig. 1, such as the inter-unit linkages $\beta-\mathrm{O}-4$ aryl ether $(\mathrm{A})$, resinol $(\beta-\beta, \mathrm{B})$ and phenylcoumaran $(\beta-5, C)$. The cross-signals of $\mathrm{C}_{\alpha}-\mathrm{H}_{\alpha}$ in $\beta-\mathrm{O}-4$ substructure are explicitly located at $\delta_{\mathrm{C}} / \delta_{\mathrm{H}} 71.8 / 4.86$, whereas the cross-signals at $\delta_{\mathrm{C}} / \delta_{\mathrm{H}} 84.3 / 4.30$ and 86.5/4.12 are attributed to its $\mathrm{C}_{\beta}-\mathrm{H}_{\beta}$ correlations linked to $\mathrm{G}$ and $\mathrm{S}$ units in $\beta-\mathrm{O}-4$ substructures, respectively. Meanwhile, the resinol $(\beta-\beta, \mathrm{B})$ was also detected, and the $\mathrm{C}_{\alpha}-\mathrm{H}_{\alpha}, \mathrm{C}_{\beta}-\mathrm{H}_{\beta}$ and $\mathrm{C}_{\gamma}-\mathrm{H}_{\gamma}$ correlations were observed at $\delta_{\mathrm{C}} / \delta_{\mathrm{H}} 85.5 / 4.67,54.1 / 3.08,71.6 / 4.21$ and 3.85 , respectively. Moreover, the phenylcoumaran $(\beta-5, \mathrm{C})$ were found at $\mathrm{C}_{\alpha}-\mathrm{H}_{\alpha}\left(\delta_{\mathrm{C}} / \delta_{\mathrm{H}} 87.1 / 5.44\right), \mathrm{C}_{\beta}-\mathrm{H}_{\beta}\left(\delta_{\mathrm{C}} / \delta_{\mathrm{H}} 54.1 / 3.73\right)$ and

Table 1 The yields and chemical compositions of original and SCEP pretreated poplar chips ${ }^{a}$

\begin{tabular}{|c|c|c|c|c|c|c|c|c|c|c|}
\hline \multirow[b]{2}{*}{ Samples } & \multirow[b]{2}{*}{ Yields (\%) } & \multicolumn{6}{|c|}{ Sugar compositions (wt\%) } & \multicolumn{3}{|c|}{ Lignin analysis (wt\%) } \\
\hline & & Ara & Gal & Glu & Xyl & Man & Total & AIL & ASL & Total \\
\hline SCEP pretreated poplar & 71.2 & $\operatorname{Tr}$ & $\operatorname{Tr}$ & 71.65 & 12.41 & 2.25 & 86.31 & 6.7 & 0.8 & 7.5 \\
\hline
\end{tabular}

${ }^{a}$ Ara, arabinose; Gal, galactose; Glu, glucose; Xyl, xylose; Man, mannose. AIL, acid insoluble lignin; ASL, acid soluble lignin. Tr: trace amount. 
EHL

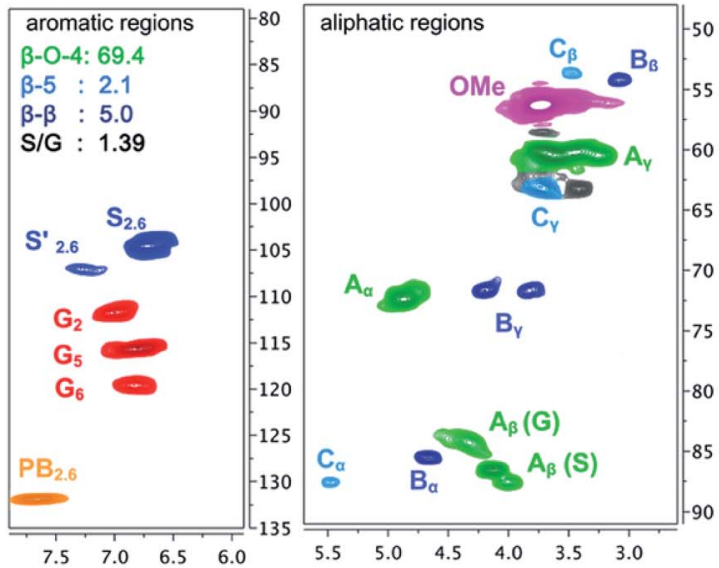

SCEP-DL

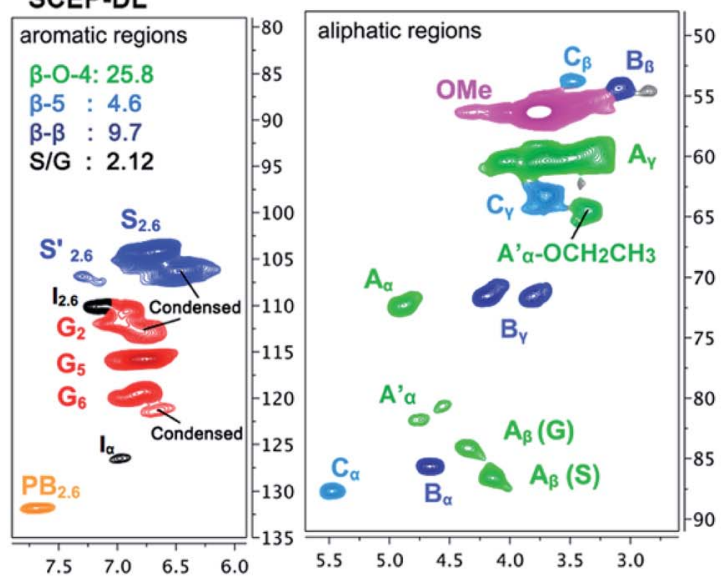

\section{SCEP-RL}
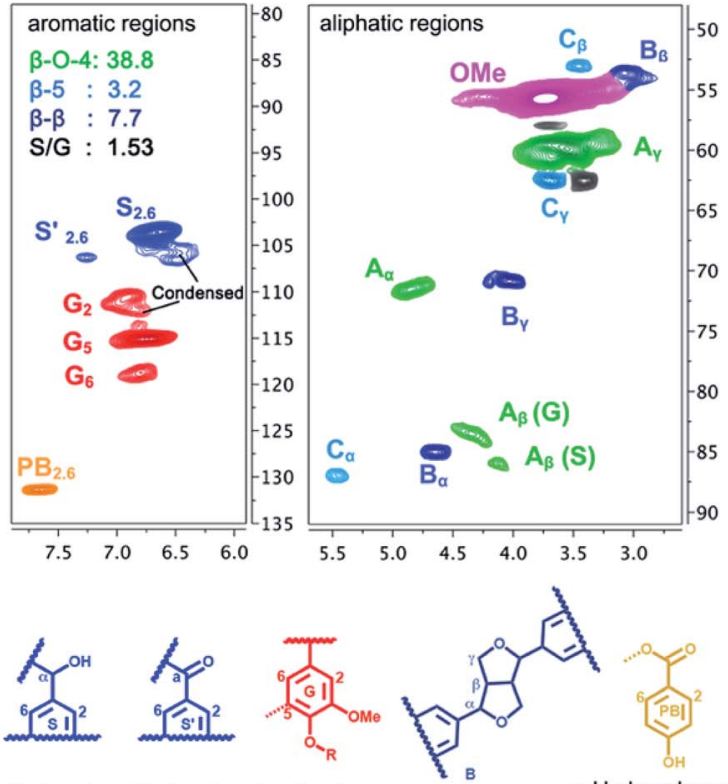

Syringyl Syringyl Guaiacyl

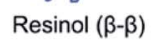

$\rho$-Hydroxybenzoate
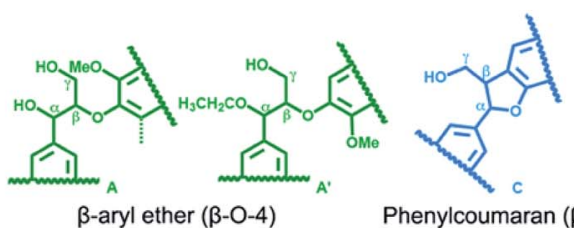

Phenylcoumaran ( $\beta-5)$ Stilbene unit

Methoxyl Unknown

structure

Fig. 1 Partial 2D-HSQC NMR spectra of EHL, SCEP-RL and SCEP-DL. Volume integrals are given for the lignin side-chain structures that are color-coded to match their signal assignments in the spectrum.

$\mathrm{C}_{\gamma}-\mathrm{H}_{\gamma}\left(\delta_{\mathrm{C}} / \delta_{\mathrm{H}} 62.9 / 3.72\right)$. In addition, the signals for the $\mathrm{C}_{\alpha}-$ oxidized $\mathrm{S}\left(\delta_{\mathrm{C}} / \delta_{\mathrm{H}} 62.9 / 3.72\right)$. In addition, the signals for the $\mathrm{C}_{\alpha^{-}}$ oxidized $\mathrm{S}$ units $\left(\mathrm{S}^{\prime}\right)$ was also observed at $\delta_{\mathrm{C}} / \delta_{\mathrm{H}} 64.5 / 3.35$. Furthermore, a minor $\mathrm{C}-\mathrm{H}_{2,6}$ aromatic correlations from $\mathrm{H}$ units $\left(\delta_{\mathrm{C}} / \delta_{\mathrm{H}} 127.9 / 7.19\right)$ could only be discovered at lower contour levels (not shown).

The structural changes of lignin during SCEP process were analyzed by comparison of the 2D-HSQC NMR spectra of EHL, SCEP-RL and SCEP-DL samples. In the aliphatic side-chain regions, two important new signals at $\delta_{\mathrm{C}} / \delta_{\mathrm{H}} 64.4 / 3.35$ and 80.6/4.55 were observed in the spectrum of SCEP-DL, which were assigned to the methylene group in $\alpha$-ethoxylated $\beta$-O- 4 linkages and the $\alpha$-position of $\alpha$-acylated $\beta$-O-4 linkages, respectively. However, these two signals were not found in the spectra of EHL and SCEP-RL preparations, indicating that the hydroxyl groups in $\alpha$-position of $\beta$-O- 4 linkages (A) were possibly replaced by the nucleophilic ethanol co-solvent and finally generated the $\alpha$-ethoxylated $\beta$-O-4 linkages $\left(\mathrm{A}^{\prime}\right){ }^{34,35}$

In contrast to the spectrum of EHL, some new correlations including the correlations at $\delta_{\mathrm{C}} / \delta_{\mathrm{H}} 106.2 / 6.51$ and 112.7/6.77, which were separately corresponded to the condensed $S_{2,6}$ and $\mathrm{G}_{2}$ units, were observed in the spectra of SCEP-DL. More importantly, the signal at $\delta_{\mathrm{C}} / \delta_{\mathrm{H}} 121.3 / 6.65$, ascribed to the condensed $\mathrm{G}$ unit, was also found was also found in the spectrum of SCEP-DL. All of these results confirmed that the recondensation reaction of lignin possibly took place during the SCEP process. Moreover, two obvious correlations at $\delta_{\mathrm{C}} / \delta_{\mathrm{H}}$ 110.0/7.16 and 126.4/6.98, which were separately assigned to the $\mathrm{C}_{2}-\mathrm{H}_{2}$ and $\mathrm{C}_{\alpha}-\mathrm{H}_{\alpha}$ in the stilbene units (I), appeared in the spectrum of SCEP-DL rather than those of EHL and SCEP-RL samples. Generally, the formation of stilbene structures was mainly attributed to the degradation of $\beta-\mathrm{O}-4$ linkages under acidic condition. ${ }^{31}$ It was previously reported that the homolytic degradation of $\beta-\mathrm{O}-4$ linkages through an quinone methide intermediate would generate novel $\beta$-1 linkages, which were then degraded into stilbene units in acidic medium. ${ }^{36}$

The quantitative analysis of the main linkages in the lignin samples were performed on the basis of previous $2 \mathrm{D}-\mathrm{HSQC}$ methods. ${ }^{37}$ As shown in Fig. 1 , the content of $\beta$-O-4 linkages in EHL was 69.4/100Ar, and it decreased to 38.8/100Ar and 25.8/ 100Ar in SCEP-RL and SCEP-DL, respectively, suggesting that the $\beta$-O-4 linkages in SCEP-RL and SCEP-DL suffered different destruction during SCEP process. The degradation of SCEP-DL was more severely than SCEP-RL. In contrast to 5.0/100Ar $\beta-$ 
$\beta$ linkages in EHL, the contents of $\beta-\beta$ linkages in SCEP-RL and SCEP-DL were increased to 7.7/100Ar and 9.7/100Ar, respectively. Meanwhile, the content of $\beta-5$ linkages were enhanced from 2.1/100Ar in EHL to 3.2/100Ar and 4.6/100Ar in SCEP-RL and SCEP-DL, respectively. These results confirmed that condensation probably occurred during the SCEP process and new $\beta-\beta$ and $\beta-5$ bonds were formed.

The changes of the S/G ratio between EHL, SCEP-RL and SCEP-DL preparations were also evaluated. It can be seen that the S/G ratio in SCEP-RL (1.53) and SCEP-DL (2.12) was higher than that of original EHL (1.39). The increase of $S / G$ ratio after SCEP process was mainly attributed to the fact that the G-type lignin was more susceptible to the condensed reaction than the S-type lignin. ${ }^{29}$

\section{3. ${ }^{13} \mathrm{C}-\mathrm{NMR}$ analysis}

The ${ }^{13} \mathrm{C}-\mathrm{NMR}$ spectra of three lignin preparations are depicted in Fig. S2. $\dagger$ The signals in the ${ }^{13} \mathrm{C}$-NMR spectra were carefully assigned according to previous literatures. ${ }^{26,27}$ To explore the mechanism of lignin structural transformation during SCEP process, the differences in the three spectra were profoundly investigated. It was observed that the spectra of SCEP-RL and SCEP-DL samples had a reduced signal at $152.3 \mathrm{ppm}$ than EHL, which was ascribed to the $\mathrm{C}_{3,5}$ in etherified $\mathrm{S}$. This result confirmed that the $\beta$-O- 4 linkages were cleaved to some extent during the SCEP process. The reduced signals at 138.1 and $149.2 \mathrm{ppm}$, corresponded to the $\mathrm{C}_{4}$ of etherified $\mathrm{S}$ units and $\mathrm{C}_{3}$ of etherified $\mathrm{G}$ units, in the spectra of SCEP-RL and SCEP-DL samples, were caused by the cleavage of etherified $G$ units after SCEP. In the spectra of SCEP-RL and SCEP-DL, the more broadened peaks at 120 and 105-110 ppm, which were assigned to the $\mathrm{G}$ and $\mathrm{S}$ units, were possibly attributed to the newly generated $\mathrm{G}$ and $\mathrm{S}$ units. This phenomenon indicated that some homologues of the common S and G units potentially formed during SCEP process.

A further comparison of the integration values for the aromatic $\mathrm{C}-\mathrm{H}(\delta 123.0-103.0 \mathrm{ppm})$, aromatic $\mathrm{C}-\mathrm{C}(\delta 140.0-123.0$ $\mathrm{ppm})$ and aromatic $\mathrm{C}-\mathrm{O}(\delta 160.0-140.0 \mathrm{ppm})$ could give detailed information on the lignin structural features. ${ }^{37}$ As depicted in Table 3, the amounts of aromatic C-O units in SCEP-DL and SCEP-RL were reduced after SCEP, whereas their contents of aromatic $\mathrm{C}-\mathrm{C}$ structures were enhanced. Considering the higher contents of $\beta-\beta$ and $\beta-5$ linkages in SCEP-DL and SCEP-

Table 3 The assignments and quantitative results of main chemical shifts in ${ }^{13} \mathrm{C}-\mathrm{NMR}$ spectra of EHL, SCEP-RL and SCEP-DL samples

\begin{tabular}{lllll}
\hline & & \multicolumn{2}{l}{ Quantitative results } \\
\cline { 3 - 5 }$\delta(\mathrm{ppm})$ & Assignments & EHL & SCEP-RL & SCEP-DL \\
\hline $160-140$ & Aromatic C-O & 1.97 & 1.87 & 1.24 \\
$140-123$ & Aromatic C-C & 1.87 & 2.10 & 2.18 \\
$123-103$ & Aromatic C-H & 2.20 & 2.11 & 1.75 \\
$91-58$ & Alkyl-O & 2.93 & 1.88 & 1.81 \\
$61.2-58$ & $\beta-O-4$ & 0.45 & 0.27 & 0.23 \\
$58-54$ & $\mathrm{OCH}_{3}$ & 1.39 & 1.35 & 1.02
\end{tabular}

RL samples (from 2D-HSQC NMR), it was concluded that some $\mathrm{C}-\mathrm{C}$ linkages were formed. This conclusion was also verified by the lower amounts of aromatic $\mathrm{C}-\mathrm{H}$ in SCEP-DL (1.75/Ar) and SCEP-RL (2.11/Ar) than those in original EHL (2.20/Ar). The phenomenon was explained by the occurred condensation reactions during SCEP process, which could be resulted the replacement of $\mathrm{C}-\mathrm{H}$ bonds by $\mathrm{C}-\mathrm{C}$ bonds. The condensation reaction commonly was postulated in competition with the hydrolysis of $\beta-\mathrm{O}-4$ ether linkages. It was also found that the amounts of $\beta-\mathrm{O}-4$ linkages in SCEP-RL (0.27/Ar) and SCEP-DL (0.23/Ar) preparations were less than that in EHL sample $(0.45 / \mathrm{Ar})$, indicating that the $\beta-\mathrm{O}-4$ linkages were preferentially to be hydrolyzed during the SCEP process. In addition, the contents of $\mathrm{OCH}_{3}$ in SCEP-DL and SCEP-RL samples were 1.35/ $\mathrm{Ar}$ and 1.02/Ar and both of them were lower than those in EHL (1.39/Ar), indicating that the demethoxylation reaction of lignin probably took place during the SCEP process.

According to the combined results of $2 \mathrm{D}-\mathrm{HSQC}$ NMR and ${ }^{13} \mathrm{C}-\mathrm{NMR}$, the breakage of the $\beta-\mathrm{O}-4$ linkages as well as demethoxylation occurred, while the $\beta-\beta$ and $\beta-5$ linkages were formed after SCEP. Besides, comparison of the 2.93/Ar alkyl-O groups in EHL, the contents of alkyl-O groups in SCEP-RL and SCEP-DL samples were obviously reduced to 1.88/Ar and 1.81/ Ar, respectively. These results implied that the majority of alkoxy side chains had been modified during SCEP process, most likely by reactions such as dehydration, shortening of the side chain and changes of alkoxy groups into carbonyl groups such as ketones, aldehydes or carboxylic acid groups (as also evidenced by the peaks at 135.5-133.7 $\mathrm{ppm}$ in ${ }^{31} \mathrm{P}$ NMR spectra).

\section{4. ${ }^{31} \mathrm{P}-\mathrm{NMR}$ analysis}

The ${ }^{31}$ P-NMR spectra of phosphytilated EHL, SCEP-RL and SCEP-DL preparations are found in Fig. S3. $\dagger$ Based on the previous method, ${ }^{34}$ the main peaks in ${ }^{31} \mathrm{P}$ NMR spectra were assigned. The peaks of aliphatic hydroxyl group (OH) located at the regions of 150.0-145.4 ppm, while the peaks of carboxylic $\mathrm{OH}$ appeared at the regions of 135.5-133.7 ppm. The peaks present at the regions of 143.7-136.9 ppm were corresponding to the phenolic $\mathrm{OH}$, including S-type $\mathrm{OH}$ (143.7-142.2 ppm) and G-type $\mathrm{OH}(140.2-138.4 \mathrm{ppm})$. The peaks at the regions of 141.4-142.2 ppm and 143.2-144.5 ppm were ascribed to the condensed phenolic $\mathrm{OH}$. The signals at the regions of 137.1$138.2 \mathrm{ppm}$ were attributed to the $\mathrm{H}$-type $\mathrm{OH}$ in lignin. The signals of cyclohexanol at the regions of 144.9-145.3 ppm were selected as the internal standard, and the amounts of various $\mathrm{OH}$ in lignin were calculated. The results are depicted in Table 4.

As shown in Table 4, the contents of aliphatic OH in EHL, SCEP-RL and SCEP-DL samples were 1.95, 1.02 and $0.70 \mathrm{mmol}$ $\mathrm{g}^{-1}$, respectively. It was concluded that the content of aliphatic $\mathrm{OH}$ in lignin was obviously reduced after SCEP process. Based on the conclusion of Brandt et al. ${ }^{38}$ and $\mathrm{Hu}$ et al. ${ }^{39}$ the decrease of aliphatic hydroxyl groups can be attributed to the loss of the $\gamma$-methylol group, as formaldehyde and hydroxyl groups on $\mathrm{C}_{\alpha, \beta}$, or the whole side chain in general to form $\beta-1^{\prime}$ linkages, which were then converted to stilbene structures (Fig. 1 I $\alpha$ 
Table 4 Structural assignments and amounts ( $\mathrm{mmol} \mathrm{g}^{-1}$ of lignin) of main signals in chemical shift ranges of ${ }^{31} \mathrm{P}-\mathrm{NMR}$ spectra of $\mathrm{EHL}$, SCEP-RL and SCEP-DL

\begin{tabular}{lllll}
\hline$\delta(\mathrm{ppm})$ & Assignment & EHL & SCEP-RL & SCEP-DL \\
\hline 150.0-145.4 & Aliphatic OH units & 1.95 & 1.02 & 0.70 \\
$143.7-142.2$ & Syringyl OH & 0.23 & 0.47 & 0.70 \\
$142.7-141.4$ & Condensed phenolic & 0.13 & 0.34 & 0.35 \\
& OH & & & \\
$142.2-138.4$ & Guaiacyl OH & 0.19 & 0.39 & 0.47 \\
$138.6-136.9$ & p-Hydroxy phenyl OH & 0.02 & 0.05 & 0.09 \\
$135.5-133.7$ & Carboxylic OH & 0.02 & 0.14 & 0.09 \\
& Total phenol & 0.57 & 1.25 & 1.61
\end{tabular}

structure). Moreover, the amounts of carboxylic OH in SCEP-RL $\left(0.14 \mathrm{mmol} \mathrm{g}^{-1}\right)$ and SCEP-DL $\left(0.09 \mathrm{mmol} \mathrm{g}^{-1}\right)$ preparations were slightly higher than that in EHL $\left(0.02 \mathrm{mmol} \mathrm{g}^{-1}\right)$, which was attributed to the oxidation of lignin during SCEP process. The results were in accordance with the reduced contents of aliphatic $\mathrm{OH}$ groups. Furthermore, the contents of condensed phenolic OH in SCEP-RL were close to those in SCEP-DL, but both of them were greatly higher than those in EHL. The amounts of G-type and S-type phenolic $\mathrm{OH}$ were also found to be increased after SCEP process. Meanwhile, the contents of total phenolic $\mathrm{OH}$ groups in lignin were obviously enhanced after pretreatment, and reached up to $1.29 \mathrm{mmol} \mathrm{g}^{-1}$ in SCEP-DL, which were almost two times as much as that in EHL $\left(0.53 \mathrm{mmol} \mathrm{g}^{-1}\right)$. The enhanced phenolic $\mathrm{OH}$ indicated the occurrence of acidic cleavage of $\beta$-O-4 linkages during SCEP process. It was also observed that enhancing rate of the G-type $\mathrm{OH}$ in SCEP-RL and SCEP-DL was slower than that of S-type $\mathrm{OH}$. This phenomenon was possibly due to that the $\mathrm{S}$ unit was highly involved in the formation of $\beta-\mathrm{O}-4$ linkages in the original lignin, and most of them could be released via the acidic cleavage reaction of $\beta$-O-4 linkages. The contents of $\mathrm{H}^{-}$ type $\mathrm{OH}$ groups in SCEP-RL and SCEP-DL were $0.05 \mathrm{mmol} \mathrm{g}^{-1}$ and $0.09 \mathrm{mmol} \mathrm{g}^{-1}$, respectively. In contrast of $0.02 \mathrm{mmol} \mathrm{g}^{-1}$ in $\mathrm{EHL}$, the contents of $\mathrm{H}$-type $\mathrm{OH}$ groups after pretreatment were not significantly enhanced even if the demethoxylation reaction occurred. This result could be explained by the undetectable products of demethoxylation of G-type units in ${ }^{31} \mathrm{P}$-NMR spectra because they were not similar to the normal $\mathrm{H}$ units. The similar phenomenon was found by Wen, et al. ${ }^{37}$

\subsection{Molecular weight analysis}

Changes in the molecular weights of lignin could provide important insights into the depolymerization of lignin during SCEP process. ${ }^{40}$ The molar mass distribution curves of EHL, SCEP-RL and SCEP-DL samples are shown in Fig. 2, in which their weight-average $\left(M_{\mathrm{w}}\right)$ molecular weights, number-average $\left(M_{\mathrm{n}}\right)$ molecular weights and polydispersity indexes $\left(M_{\mathrm{w}} / M_{\mathrm{n}}\right.$, PDI) are also summarized. The $M_{\mathrm{n}}$ of EHL was $5952 \mathrm{~g} \mathrm{~mol}^{-1}$, which was reduced by $29 \%$ to $4189 \mathrm{~g} \mathrm{~mol}^{-1}$ in SCEP-RL and further by $58 \%$ to $2494 \mathrm{~g} \mathrm{~mol}^{-1}$ in SCEP-DL. It was deduced that the lignin was greatly degraded via the depolymerization after SCEP process, which were also confirmed by the decreased amounts of $\beta-\mathrm{O}-4$

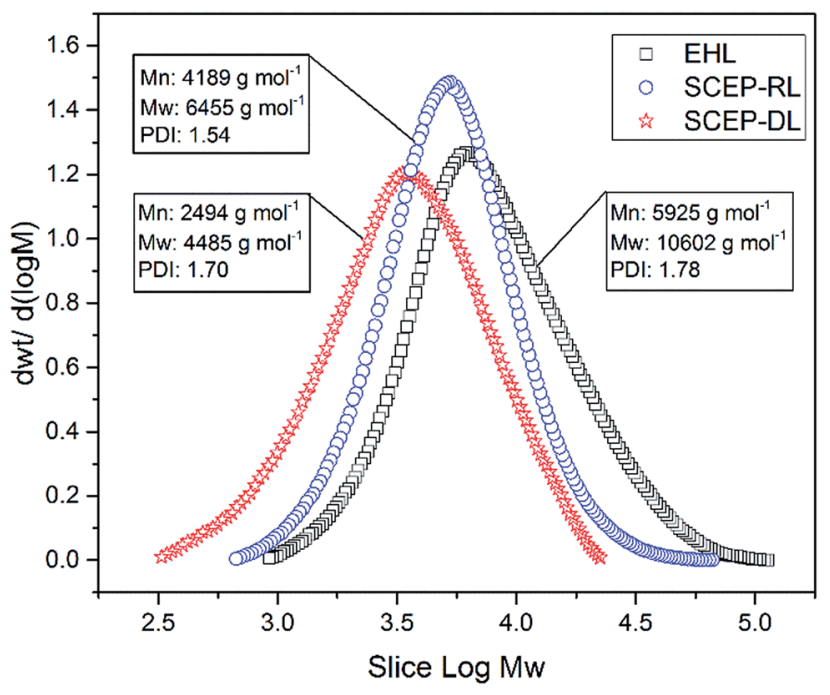

Fig. 2 The GPC curves of EHL, SCEP-RL and SCEP-DL samples.

linkages in SCEP-DL and SCEP-RL samples as determined by 2D-HSQC NMR and ${ }^{13} \mathrm{C}-\mathrm{NMR}$ techniques. Besides the molecular weight, the PDI was also found to be decreased from 1.78 in EHL to 1.54 in SCEP-RL and 1.70 in SCEP-DL, respectively, suggesting that the structures of SCEP-RL and SCEP-DL were more homogeneous than those of EHL. Furthermore, the SCEP-DL exhibited relatively lower molecular weights and PDI value than SCEP-RL, suggesting that the depolymerization of lignin dissolving in pretreatment liquors was more severely than those exiting in the pretreated residues. This phenomenon was also verified by the lower contents of the sensitive linkages in SCEP-DL than SCEPRL. Due to their smaller molecular weights and higher amounts of hydroxyl groups, the SCEP-DL had excellent solubility in ethanol-water solutions. Therefore, we could get the degraded lignin products with homogeneous structures from SCEP liquors, which were ideal raw materials to be functionalized into other high-value materials. ${ }^{36}$

\subsection{Thermogravimetric analysis}

The thermogravimetric weight loss curves (TGA) of EHL, SCEPRL and SCEP-DL samples and their first derivative curves (DTGA) are shown in Fig. 3. It was found that the thermodecomposition of three lignin samples took place in the temperature range of $200-600{ }^{\circ} \mathrm{C}$. Generally, majority of aryl ether bond linkages were degraded at the temperature range of $200-350^{\circ} \mathrm{C}$. In this decomposing temperature range, the weight losses for SCEP-RL and SCEP-DL samples were separately $26.8 \%$ and $25.1 \%$, both of which were lower than $42.7 \%$ for EHL. These results indicated that the thermal stability of SCEP-RL and SCEP-DL were higher than that of EHL at the initial decomposing phase, which were mainly attributed to their lower contents of $\beta-\mathrm{O}-4$ linkages. Furthermore, the weight losses of SCEP-RL (13.6\%) and SCEP-DL (11.0\%) were higher than that of EHL (7.6\%) in the decomposing temperature of $350{ }^{\circ} \mathrm{C}$ to $400{ }^{\circ} \mathrm{C}$, the increased decomposition rate was attributed to the oxidation and degradation of side chains in lignin, i.e., 


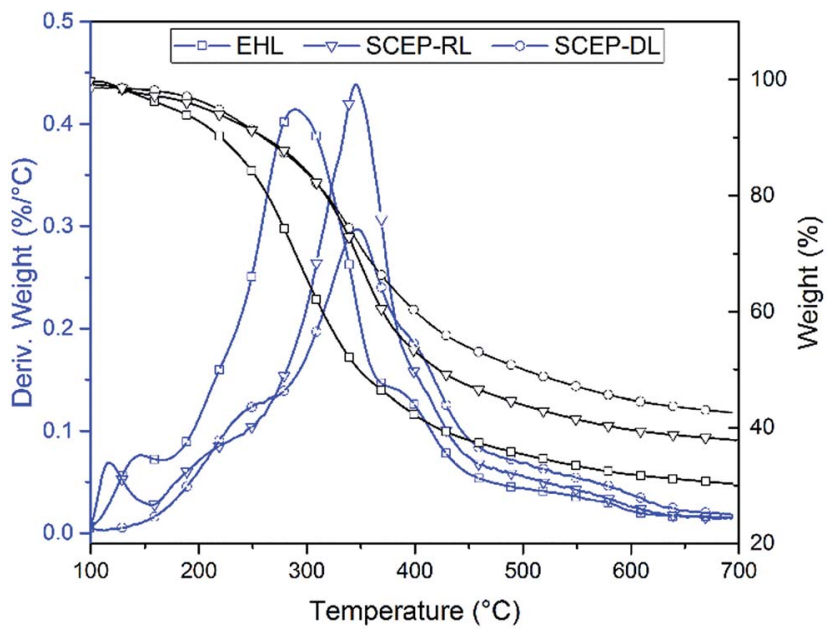

Fig. 3 Thermogravimetric curves and derivative thermogravimetry curves of EHL, SCEP-RL and SCEP-DL.

carbonylation or carboxylation of aliphatic $\mathrm{OH}$ and dehydrogenation reaction of side chains the lignin side chain.

The aromatic rings and $\mathrm{C}-\mathrm{C}$ linkages (e.g., $\beta-\beta$ and $\beta-5$ linkages) were decomposed when the temperature was above $400{ }^{\circ} \mathrm{C}$. In the temperature of $400{ }^{\circ} \mathrm{C}$ to $600{ }^{\circ} \mathrm{C}$, the weight losses of SCEP-RL and SCEP-DL were $14.6 \%$ and $17.5 \%$, which were higher than that of EHL $(11.9 \%)$. These results indicated that more amounts of resistant $\beta-\beta$ and $\beta-5$ linkages were formed during SCEP process. Meanwhile, it was found that the weight values of char residues at $600{ }^{\circ} \mathrm{C}$ were $30.3 \%$ in EHL, $37.8 \%$ in SCEP-RL and $42.6 \%$ in SCEP-DL, indicating that more condensed lignin structures were generated after SCEP process, as also revealed by the aforementioned results in ${ }^{13} \mathrm{C}$-NMR and 2D-HSQC-NMR spectra.

In addition, the maximum decomposition temperatures $\left(T_{\mathrm{m}}\right)$ of lignin were observed to be enhanced from $289^{\circ} \mathrm{C}$ in EHL to $344^{\circ} \mathrm{C}$ in SCEP-RL and $349^{\circ} \mathrm{C}$ in SCEP-DL, which was probably due to the generation of more stable lignin structures (e.g. condensed structures) during SCEP process.

\subsection{Delignification mechanism during SCEP process}

It was found that almost $79 \%$ lignin was removed from poplar chips after SCEP at $120^{\circ} \mathrm{C}$ in this study. However, the delignification efficiency was only $52 \%$ after organosolv pretreatment at $165^{\circ} \mathrm{C}$, which only used the water-ethanol as pretreatment liquor without addition of $\mathrm{ScCO}_{2}{ }^{41}$ It was concluded that the combined usage of $\mathrm{ScCO}_{2}$ and ethanol-water into organosolv pretreatment was beneficial to isolation of lignin from biomass, which was mainly as a result of the strongly acidic environment caused by the dissolution of $\mathrm{ScCO}_{2}$ into water. After dissolving $\mathrm{ScCO}_{2}$ into water, the carbonic acid was in situ generated and dissociated via two steps as reference with the following equations.

$$
\begin{gathered}
\mathrm{CO}_{2}+\mathrm{H}_{2} \mathrm{O} \leftrightarrow \mathrm{HCO}_{3}{ }^{-}+\mathrm{H}_{3} \mathrm{O}^{+} ; \\
\mathrm{HCO}_{3}{ }^{-}+\mathrm{H}_{2} \mathrm{O} \leftrightarrow \mathrm{CO}_{3}{ }^{2-}+\mathrm{H}_{3} \mathrm{O}^{+} ;
\end{gathered}
$$

Therefore, the hydrolysis of biomass, especially hemicelluloses and lignin, was promoted. According to the results of NMR, the mechanism of delignification during the process of SCEP was proposed and is shown in Fig. 4. The resulted included: (1) the cleavage of $\beta-\mathrm{O}-4$ linkages would enhance the

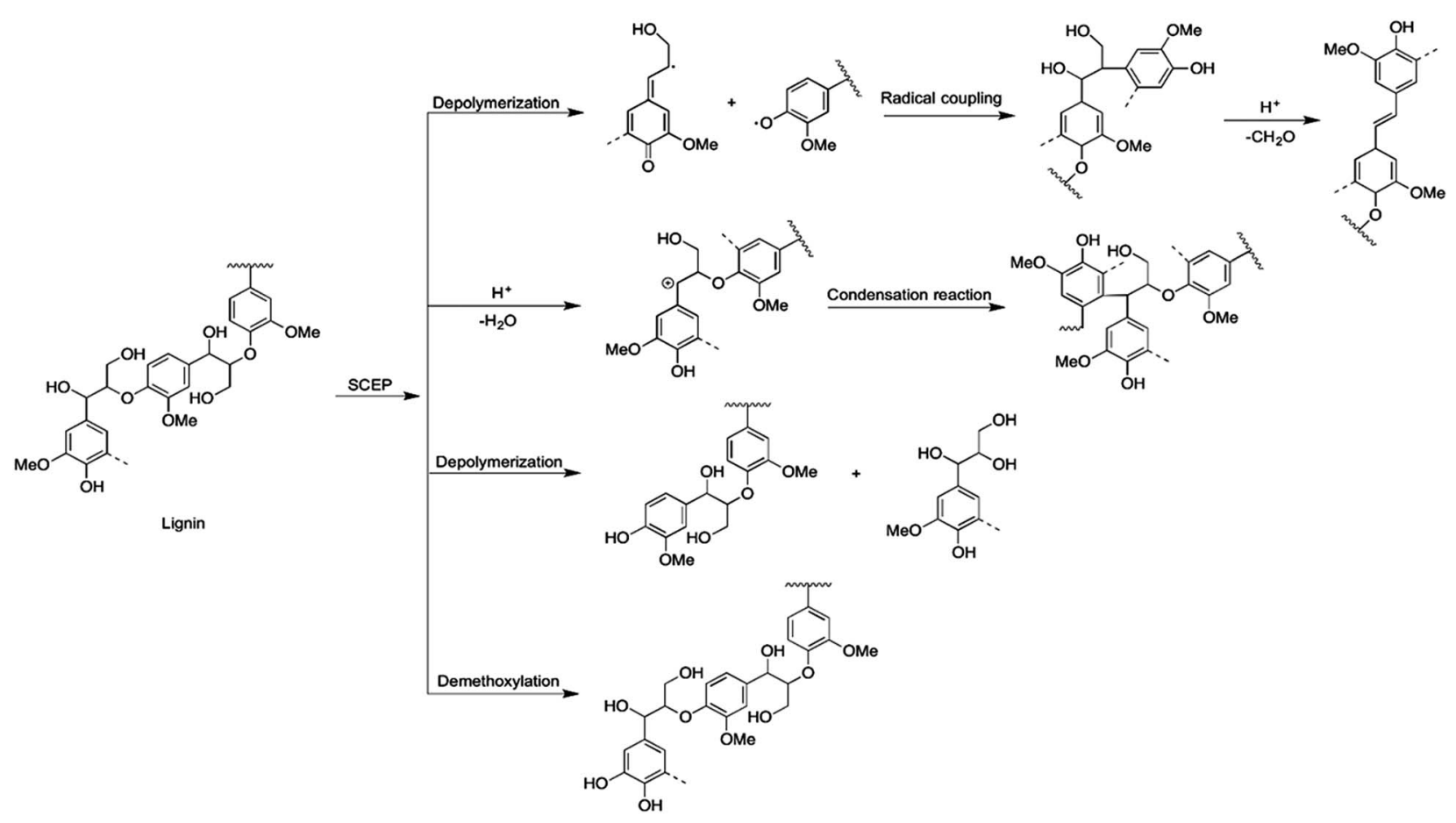

Fig. 4 The proposed delignification reaction mechanism during SCEP process. 
amount of phenolic $\mathrm{OH}$, while the dehydration reaction could reduce the content of aliphatic $\mathrm{OH}$. (2) The $\beta-1$ interlinkages were formed via the homolytic cleavage of $\beta-\mathrm{O}-4$ with quinone methide intermediate, which then were degraded under acidic medium and generating the stilbenes structures through loss of the $\gamma$-methylol group as formaldehyde. (3) The condensation reaction commonly occurred through the couple reaction between the cationic carbons at $\mathrm{C}_{\alpha}$ position of side chain and the free $\mathrm{C}_{5}$ or $\mathrm{C}_{6}$ position in another units of lignin another lignin unit (i.e., through the).$^{36}$ (4) The demethoxylation reaction of lignin probably took place during the process of SCEP.

\section{Conclusions}

The structural changes of lignin from poplar during SCEP process were illustrated by comparison of the chemical features of SCEPRL and SCEP-DL samples with original EHL. After SCEP process, $79 \%$ of lignin was degraded and dissolved into the SCEP liquors. The SCEP-RL and SCEP-DL possessed higher amounts of free phenolic and carboxyl $\mathrm{OH}$ groups and lower molecular weights than EHL, which was mainly caused by the extensive cleavage of $\beta$ O-4 linkages, as evidenced by the quantitative results of ${ }^{13} \mathrm{C}-\mathrm{NMR}$, 2D-HSQC-NMR, ${ }^{31} \mathrm{P}-\mathrm{NMR}$, and GPC techniques. The founding for structural changes of lignin during SCEP process would give some highlights for optimizing, controlling the pretreatment process and obtaining the biomass residues with easily hydrolyzing property. Moreover, the well-defined and active lignin polymers isolated from biomass by SCEP could be utilized as the raw materials to develop value-added chemical products.

\section{Acknowledgements}

The authors are grateful for the support by National Natural Science Foundation of China (No 31170554 and No 31470604), the Fundamental Research Funds for Dalian Polytechnic University (No 2016J001) and the 6th Session of Geping Green Action-123 Project of Liaoning Environmental Research and Education (No. CEPF2013-123-1-10).

\section{Notes and references}

1 R. Ravindran and A. K. Jaiswal, Bioresour. Technol., 2016, 199, 92-102.

2 C. Liu, J. Hu, H. Zhang and R. Xiao, Fuel, 2016, 182, 864-870. 3 S. K. Jang, H. Y. Kim, H. S. Jeong, J. Y. Kim, H. Yeo and I. G. Choi, Renewable Energy, 2016, 87, 599-606.

4 H. Yang, Y. Xie, X. Zheng, Y. Pu, F. Huang, X. Meng, W. Wu, A. Ragauskas and L. Yao, Bioresour. Technol., 2016, 207, 361369.

5 C. S. Lancefield, I. Panovic, P. J. Deuss, K. Barta and N. J. Westwood, Green Chem., 2017, 19, 202-214.

6 S. N. Sun, S. L. Sun, X. F. Cao and R. C. Sun, Bioresour. Technol., 2016, 199, 49-58.

7 S. McIntosh and T. Vancov, Bioresour. Technol., 2010, 101, 6718-6727.

8 M. Brahim, N. Boussetta, N. Grimi, E. Vorobiev, I. ZiegerDevin and N. Brosse, Ind. Crops Prod., 2017, 95, 643-650.
9 T. A. Lloyd and C. E. Wyman, Bioresour. Technol., 2005, 96, 1967-1977.

10 K. Zhang, Z. Pei and D. Wang, Bioresour. Technol., 2016, 199, 21-33.

11 Z. Zhang, M. D. Harrison, D. W. Rackemann, W. O. S. Doherty and I. M. O'Hara, Green Chem., 2016, 18, 360-381.

12 L. V. Daza Serna, C. E. Orrego Alzate and C. A. Cardona Alzate, Bioresour. Technol., 2016, 199, 113-120.

13 M. Paljevac, M. Primožič, M. Habulin, Z. Novak and Ž. Knez, J. Supercrit. Fluids, 2007, 43, 74-80.

14 G. Simeoni, T. Bryk, F. A. Gorelli, M. Krisch, G. Ruocco, M. Santoro and T. Scopigno, Nat. Phys., 2010, 6, 503-507.

15 H. Lv, L. Yan, M. Zhang, Z. Geng, M. Ren and Y. Sun, Chem. Eng. Technol., 2013, 36, 1899-1906.

16 D. Pasquini, M. T. B. Pimenta, L. H. Ferreira and A. A. S. Curvelo, J. Supercrit. Fluids, 2005, 34, 125-131.

17 E. Kiran and H. Balkan, J. Supercrit. Fluids, 1994, 7, 75-86.

18 S. Cheng, I. D'cruz, M. Wang, M. Leitch and C. Xu, Energy Fuels, 2010, 24, 4659-4667.

19 H. Lü, M. Ren, M. Zhang and Y. Chen, Chin. J. Chem. Eng., 2013, 21, 551-557.

20 D. Pasquini, M. T. B. Pimenta, L. H. Ferreira and A. A. D. S. Curvelo, J. Supercrit. Fluids, 2005, 36, 31-39.

21 M. Gao, F. Xu, S. Li, X. Ji, S. Chen and D. Zhang, Biosystems Engineering, 2010, 106, 470-475.

22 N. Narayanaswamy, A. Faik, D. J. Goetz and T. Gu, Bioresour. Technol., 2011, 102, 6995-7000.

23 N. Srinivasan and L. K. Ju, Bioresour. Technol., 2010, 101, 9785-9791.

24 J. L. Rahikainen, R. Martin-Sampedro, H. Heikkinen, S. Rovio, K. Marjamaa, T. Tamminen, O. J. Rojas and K. Kruus, Bioresour. Technol., 2013, 133, 270-278.

25 A. Sluiter, B. Hames, R. Ruiz, C. Scarlata, J. Sluiter, D. Templeton and D. Crocker, Laboratory Analytical Procedures, 2008, 1617.

26 T. Q. Yuan, S. N. Sun, F. Xu and R. C. Sun, J. Agric. Food Chem., 2011, 59, 6605-6615.

27 Y. Tobimatsu, F. Chen, J. Nakashima, L. L. EscamillaTrevino, L. Jackson, R. A. Dixon and J. Ralph, Plant Cell, 2013, 25, 2587-2600.

28 B. L. Xue, J. L. Wen, F. Xu and R. C. Sun, J. Appl. Polym. Sci., 2013, 129, 434-442.

29 Y. Pu, S. Cao and A. J. Ragauskas, Energy Environ. Sci., 2011, 4, 3154.

30 Y. X. An, N. Li, H. Wu, W. Y. Lou and M. H. Zong, ACS Sustainable Chem. Eng., 2015, 3, 2951-2958.

31 B. Wang, X. J. Shen, J. L. Wen and R. C. Sun, RSC Adv., 2016, 6, 57986-57995.

32 C. G. Yoo, S. Zhang and X. Pan, RSC Adv., 2017, 7, 300-308.

33 F. Zikeli, T. Ters, K. Fackler, E. Srebotnik and J. Li, Ind. Crops Prod., 2016, 85, 309-317.

34 Y. Z. Guo, J. H. Zhou, J. L. Wen, G. W. Sun and Y. J. Sun, Ind. Crops Prod., 2015, 76, 522-529.

35 J. L. Wen, B. L. Xue, S. L. Sun and R. C. Sun, J. Chem. Technol. Biotechnol., 2013, 88, 1663-1671. 
36 B. B. Hallac, Y. Pu and A. J. Ragauskas, Energy Fuels, 2010, 24, 2723-2732.

37 J. L. Wen, T. Q. Yuan, S. L. Sun, F. Xu and R. C. Sun, Green Chem., 2014, 16, 181-190.

38 A. Brandt, L. Chen, B. E. van Dongen, T. Welton and J. P. Hallett, Green Chem., 2015, 17, 5019-5034.
39 G. Hu, C. Cateto, Y. Pu, R. Samuel and A. J. Ragauskas, Energy Fuels, 2012, 26, 740-745.

40 J. Li, G. Henriksson and G. Gellerstedt, Bioresour. Technol., 2007, 98, 3061-3068.

41 N. Kang, L. Zhong, L. F. Hui, C. L. Si, C. Li, T. Zhao and S. T. Mao, BioResources, 2011, 7, 578-592. 